\title{
Tackling the Pharmaceutical Frontier: Regulation of Cannabinoid-Based Medicines in Postwar Japan
}

\author{
Tempei Miyaji, ${ }^{1, *}$ Michiyuki Nagasawa, ${ }^{2}$ Takuhiro Yamaguchi, ${ }^{1,3}$ and Kiichiro Tsutani ${ }^{4}$
}

\begin{abstract}
Background: The valley of death, which refers to the gap due to the lack of support for the translation of basic research to related clinical studies, exists in the field of translational cannabinoid research in Japan owing to regulations. Article 4 of the Cannabis Control Act (CCA) of 1948 prohibits the use of Cannabis-based medicines.

Objectives: This study aimed to explore the history of the establishment of regulations on the medical use of Cannabis-based medicines and discuss the current status of cannabinoid research and its regulation in Japan.

Methods: We conducted a literature review of nationally archived official documents from the end of World War II in 1945 to 1948, which is the year the CCA was established. The documents were examined, specifically focusing on the sequence of events.

Results: We found three memoranda related to the establishment of the CCA. The establishment of law on controlling narcotics was instructed by the general headquarters (GHQ)/Supreme Commander for the Allied Powers (SCAP) during the period of occupation after World War II. However, the Japanese Government decided to regulate Cannabis separately from other narcotics. Item (ii) of article 4 in the CCA, which prohibits medical application of Cannabis, was included to protect farmers growing Cannabis for the hemp content.

Conclusion: Current Japanese regulations prohibiting clinical research in phytocannabinoids were instituted during the postwar era of World War II. Scientific discoveries have advanced cannabinoid research and have led positive reforms of the regulation of Cannabis in other countries. Therefore, there is ample motivation and opportunity for Japanese stakeholders to revise article 4 of the CCA for the benefit of patients.
\end{abstract}

Key words: regulation; medical marijuana; pharmaceuticals; phytocannabinoids; valley of death

\section{Introduction}

Over 200 research studies on cannabinoids, including the endocannabinoid system, have been funded by the Grants-in-Aid for Scientific Research of the Ministry of Education, Culture, Sports, Science and Technology (MEXT) of Japan from 1897 to 2014 . $^{1}$ For example, the endocannabinoid, 2-arachidonoylglycerol, was discovered by the Japanese researchers Sugiura et al. ${ }^{2}$ simultaneously with Mechoulam et al. ${ }^{3}$ in Israel in 1995.
Furthermore, more than 10 of these funded studies were intended to innovate drug development or the clinical application of cannabinoids. ${ }^{1}$ However, the valley of death, which refers to the gap due to the lack of funding and other support for related clinical studies, exists in cannabinoid translational research owing to Japanese regulations. As a result, clinical studies on phytocannabinoids have not been conducted since 1948. In contrast, a number of clinical studies conducted on cannabinoids,

\footnotetext{
${ }^{1}$ Department of Clinical Trial Data Management, Graduate School of Medicine, The University of Tokyo, Tokyo, Japan.

${ }^{2}$ Department of Pharmaceutical Regulatory Science, Graduate School of Pharmaceutical Sciences, The University of Tokyo, Tokyo, Japan.

${ }^{3}$ Division of Biostatistics, Tohoku University Graduate School of Medicine, Sendai, Japan.

${ }^{4}$ Graduate School of Pharmaceutical Sciences, The University of Tokyo, Tokyo, Japan.
}

*Address correspondence to: Tempei Miyaji, MS, Department of Clinical Trial Data Management, Graduate School of Medicine, The University of Tokyo, 7-3-1 Hongo, Bunkyo-ku, Tokyo 1138655, Japan, E-mail: tmiyaji@m.u-tokyo.ac.jp

(c) Tempei Miyaji et al. 2016; Published by Mary Ann Liebert, Inc. This Open Access article is distributed under the terms of the Creative Commons License (http://creativecommons.org/licenses/by/4.0), which permits unrestricted use, distribution, and reproduction in any medium, provided the original work is properly credited. 
including phytocannabinoids, internationally in other countries have already demonstrated their various therapeutic effects in a wide range of common symptoms and rare diseases such as pain, nausea and vomiting, anorexia, depression, epilepsy, and multiple sclerosis by clinical trials. ${ }^{4}$

Figure 1 shows relevant articles on Cannabis or cannabinoids based on their publication year from 1950 to 2014 that are listed in PubMed. Pharmaceutical and medical research on cannabinoids has accelerated rapidly since the discovery of the endocannabinoid system in the human body in the early 1990s. The development and approval of cannabinoid-based medicine have occurred in European countries and the United States. ${ }^{6,7}$ Moreover, the medical use of Cannabis has been authorized under state laws in 23 states and the District of Columbia in the United States as of 2015, including through the Compassionate Use Act. ${ }^{8}$ Furthermore, a major nonpsychoactive cannabinoid, cannabidiol, has been registered by the US Food and Drug Administration and the European Medicines Agency as an orphan drug for the treatment of Dravet syndrome. ${ }^{9,10}$

Although the regulations controlling cannabinoidbased medicine have been positively reformed in other countries, the medical use of Cannabis or its components is still strictly prohibited in Japan, and the research in this area is limited to nonclinical studies. Items (ii)-(iii) of paragraph (1) of article 4 in the Cannabis Control Act (CCA, Taimatorishimarihou, 大麻取締法) ${ }^{11}$ prohibit the medical use of Cannabis with no exceptions for compassionate use or clinical trials. Given below is a quote from related articles of the current version of the CCA (Enactment: Act No. 124 of 1948; Item (iii) was added: Act No. 108 of 1968; Item (iv) was added: Act No. 33 of 1990; Last revision: Act No. 160 of 1999). ${ }^{12}$

Article 1 The term "Cannabis" as used in this Act means the cannabis plant (Cannabis Sativa L.) and its products, provided, however, that the grown stalk of the cannabis plant and its products (excluding resin.) and the seed of cannabis plant and its products are excluded.

Article 4 (1) It is prohibited for any person to commit the following acts:

(i) Importing or exporting Cannabis (excluding cases where the Cannabis Researcher receives authorization from the Minister of Health, Labour and Welfare and imports or exports Cannabis.);

(ii) Treatment with medicines manufactured from Cannabis or distributing it for treatment;

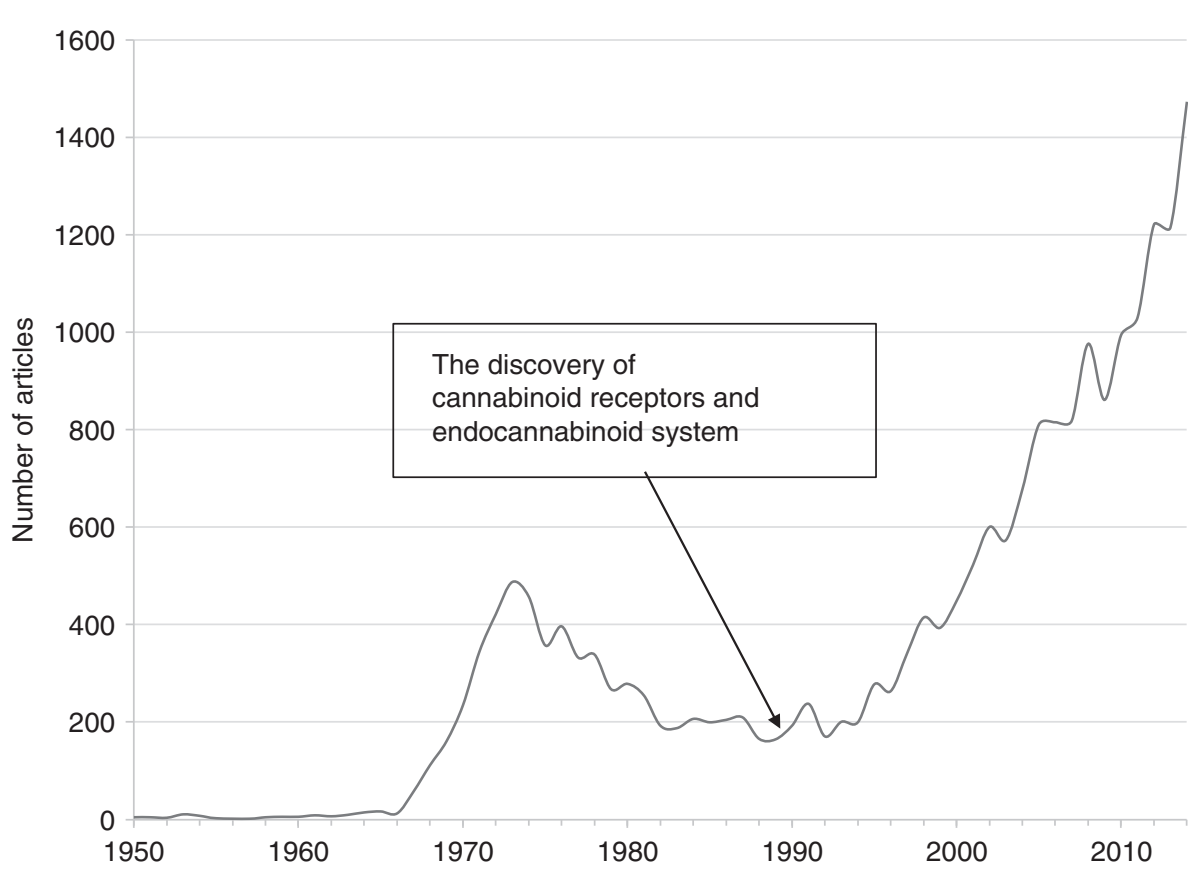

FIG. 1. Number of articles related to cannabis or cannabinoids on Pubmed. 
(iii) Receiving treatment with medicines manufactured from Cannabis;

(iv) Advertising Cannabis, except the cases where it is advertised in newspapers or magazines for persons related to pharmaceuticals, etc., (meaning persons related to pharmaceuticals or persons who are engaged in natural science research. The same applies hereinafter in this item.) with articles concerning medical affairs, pharmaceutical affairs, or natural sciences and in other cases where it is advertised mainly to persons related to pharmaceuticals, etc.

The aim of this study is to explore the history of the establishment of regulations on the medical use of Cannabis-based medicines and to further discuss the current status of cannabinoid research and its control in Japan.

\section{Methods}

We conducted a thorough literature review of nationally archived official documents from the end of World War II in 1945 to 1948 when the CCA was established. The data were electronically collected by searching PubMed, CiNii books, and the database of the Ichushi (Japan Medical Abstract Society) Web. In addition, the Supreme Commander for the Allied Powers (SCAP) Instruction Note (SCAPIN) was manually searched at the Constitutional Government Reference Room, and the Proceedings of the Diet of the Japanese Government were also electronically searched using the search system of the National Diet Library of Japan. ${ }^{.3}$

The collected documents were examined, specifically focusing on information related to the sequence of the events leading to the establishment of the regulations. No official English translation of the Diet Records was found and therefore we translated them in accordance with the Standard Legal Term Dictionary, version $10 .{ }^{14}$ In this study, we defined Cannabis-based medicine as medicinal products manufactured from Cannabis plants that contain natural phytocannabinoids. Additionally, cannabinoid-based medicine is defined as the medicinal product that includes all ligands of the cannabinoid receptors and related compounds. ${ }^{4}$

\section{Results}

General headquarters memoranda regulating narcotics

After the end of World War II, Japan was under allied occupation until the Treaty of San Francisco was enforced in 1952. There were 2204 memoranda or instructions in the so-called SCAPIN issued from the general headquarters (GHQ)/SCAP to the Japanese Government to order various kinds of administrative actions or basic measures. ${ }^{15}$ We discovered three memoranda relating to the establishment of the CCA, which were the SCAPIN 130, 644, and 4053-A.

In SCAPIN 130 entitled "Control of Narcotic Products and Records in Japan," which was instructed on October 12, 1945, the planting and cultivation of narcotic seeds or plants (Supplementary Appendix S1) ${ }^{16}$ as well as importation of related products were prohibited. In paragraph 6, marijuana (Cannabis sativa L.) was defined as a narcotic along with opium, cocaine, morphine, and heroin. In addition, in section $\mathrm{C}$ of the same paragraph, physicians and apothecaries were included as subjects in this memorandum.

On January 22, 1946, SCAPIN 644 entitled "Establishment of an Effective System for Narcotic Control in Japan" was instructed to the Japanese Government (Supplementary Appendix S2) ${ }^{17}$ and ordered the enactment of the law for narcotic control. Furthermore, in SCAPIN 130, the importation of narcotic products was allowed with the authorization of SCAP, and this memorandum expressed nine requirements for dealing in narcotics, including registration, licensing, and reporting.

On June 28, 1947, SCAPIN 4053-A, which is the amended SCAPIN 130, was instructed (Supplementary Appendix S3). ${ }^{15}$ Although in SCAPIN 130 the importation and production of narcotics were thoroughly prohibited, paragraph 2 of this memorandum states that "permit the manufacture of finished medicinal narcotic drugs as required for the medical needs of the Japanese people." Although the instructions of the memorandum limited the manufacture, importation, and exportation of narcotics, the medical use of narcotic drugs manufactured from Cannabis was not prohibited by the GHQ/SCAP and therefore medical applications were an exception as of June 1947.

\section{Debate of the Japanese Diet Committee}

After receiving these memoranda, the Welfare Committee of the Diet held a preparatory meeting to discuss enacting the law of narcotic control. Table 1 chronologically presents the events related to the establishment of the CCA. Before the medicinal aspects of Cannabis were mentioned in the Diet memorandum, there had been concerns raised by farmers because it has been inseparably linked to Japanese spirituality and lifestyle 
Table 1. Events Related to the Establishment of the Cannabis Control Act

\begin{tabular}{|c|c|}
\hline Date & Event \\
\hline 12 October, 1945 & $\begin{array}{l}\text { SCAPIN } 130 \text { "Control of Narcotic Products } \\
\text { and Records in Japan" instructed }\end{array}$ \\
\hline 22 January, 1946 & $\begin{array}{l}\text { SCAPIN } 644 \text { "Establishment of an effective } \\
\text { System for Narcotic Control in Japan" } \\
\text { instructed }\end{array}$ \\
\hline 28 June, 1947 & $\begin{array}{l}\text { SCAPIN 4053-A "Authorization to } \\
\text { Manufacture Narcotics in Japan" } \\
\text { instructed }\end{array}$ \\
\hline 12, 15-17 June, 1948 & $\begin{array}{l}\text { Deliberation at The Welfare Committee } \\
\text { of the House of Representatives }\end{array}$ \\
\hline 19 June, 1948 & Deliberation at The House of Representatives \\
\hline 24-25 June, 1948 & $\begin{array}{l}\text { Deliberation at The Welfare Committee } \\
\text { of the House of Councilors }\end{array}$ \\
\hline 28 June, 1948 & Deliberation at The House of Councilors \\
\hline 10 July, 1948 & CCA promulgated and enforced \\
\hline 1 March, 1951 & $\begin{array}{l}\text { Three commodities of Cannabis-based } \\
\text { medicines were deleted from the sixth } \\
\text { edition of Japanese Pharmacopoeia }\end{array}$ \\
\hline 17 March, 1953 & $\begin{array}{l}\text { Cannabis seeds were excluded from } \\
\text { the control }\end{array}$ \\
\hline $21 \mathrm{Ju}$ & Item (iii) was added in article 4 of CCA \\
\hline 19 June, 1990 & Item (iv) was added in article 4 of CCA \\
\hline
\end{tabular}

CCA, Cannabis Control Act; SCAPIN, Supreme Commander for the Allied Powers Instruction Note.

from ancient times. While the origins of hemp are not entirely clear, hemp was most certainly first imported to the island of Kyushu from China through Korea in the Neolithic Jomon Period (10,000-300 BC).$^{18}$ Cannabis has been used as textiles, foods, and medicines, as well as in the Shinto rituals. Cannabis was already subject to control by the revised International Opium Convention adopted by the Second Opium Conference of 1925, which Japan ratified in 1928 and implemented as the Narcotics Control Regulation in 1930. However, the use of Cannabis for medical and scientific purposes was exempted by the convention. ${ }^{19}$ There was a huge demand for hemp fiber from Cannabis for national restoration during the postwar era ${ }^{20}$ and therefore there were concerns regarding placing restrictions on its cultivation among farmers.

Given below is the statement of Mr. Kihachiro Honma, a member of the Petition Committee of the House of Representatives (HoR), June 3, 1947. ${ }^{21}$

"Cannabis has a very wide range of use, thus it is a very important substance. However, the cultivation of Cannabis plant was prohibited due to the narcotic effects of the active ingredient in Cannabis as mentioned above. I, as a staff of Ministry of Agriculture and Forestry, have supplicated to GHQ/SCAP for the cultivation to continue so that farmers growing hemp fiber will not be damaged economically and the present imbalance of supply and demand on hemp products will be dissolved."
Therefore, considering the impact of the prohibitory laws on agricultural cash crop cultivation, a member of the Welfare Committee of the HoR proposed a separation of the law of Cannabis and that of other narcotics, which would allow farmers to cultivate hemp with fewer restrictions compared with plants that are raw material for narcotics. Given below is the statement of the Minister of State, Mr. Giichi Takeda, presented at the Welfare Committee of the HoR on June 12, $1948 .^{21}$

"I would now like to address the topic of conversation, the draft of CCA. Because the resin contained in the Cannabis plant has narcotic effects, Cannabis has been cracked down as a narcotic. Most people who are cultivating Cannabis plant are in agriculture, and those who will be subjected to the license system by the draft of Narcotics Control Act (NCA) are in vastly different occupations, such as doctors, dentists, and pharmacists, etc., making the draft of CCA a good balance considering this situation and perfecting enforcement. This is the reason why the draft was submitted separately from the draft of NCA."

Following the passing of the CCA draft by the HoR, further discussions on the use of Cannabis-based medicines were conducted in the House of Councilors (HoC). Item (ii) of article 4 was intended to control products that had already been distributed in the market and given below is the discussion that ensued between two members of the Welfare Committee of the HoC on June $25,1948^{21}$;

Mr. Ryuen Kusaba asked,

"Article 4 mentions the term "treatment," which I heard includes the prescriptions of a drug manufactured from Cannabis. If the basis of this Act is that all drugs manufactured from Cannabis are to be prohibited, there will be no treatment with medicines manufactured from Cannabis. Then, the term "treatment" is unnecessary, leading us to question why item (ii) is submitted with such contradiction."

Mr. Katsuji Kuge (a staff of the Ministry of Health and Welfare) subsequently responded,

"I will take this question. We think that previously manufactured Cannabis-based medicines still remain in Japan. Regarding such meaning, this item has been added in article 4."

However, the proceedings of the Diet discussion on the medical use of Cannabis only involved the above conversations, and the draft of CCA was subsequently passed by the Welfare Committee of the HoC on June 25, 1948, and by the HoC itself on June 28, 1948. 


\section{Establishment of CCA}

On July 10, 1948, the CCA was promulgated and enforced. Three commodities concerning Cannabisbased medicines were listed in the Japanese Pharmacopoeia, namely Cannabis indica, Extractum Cannabis indica (1st edition, 1886), and Tinctura Cannabis indicae (4th edition, 1920); however, these items were deleted in the review process of the sixth edition (1951). ${ }^{19}$ Since then and to date, both the clinical use of Cannabis-based medicines and related clinical studies have been prohibited in Japan.

\section{Discussion}

\section{Separation of CCA and NCA}

The establishment of the law controlling Cannabis was initially led by the GHQ/SCAP in the postwar period following World War II and it was instructed along with other narcotic control measures. In describing the related SCAPIN, the GHQ/SCAP exempted the use of narcotics for the medical needs of Japanese people from prohibition by SCAPIN 4053-A. We were unable to locate records of the negotiations between the GHQ/SCAP and the Japanese Government in this present study. However, from the available information in the Diet Records, the Japanese Government appeared to have made a proposal for the separation of the CCA and the NCA to the GHQ/ SCAP to protect farmers and enable them to continue to engage in hemp agricultural production.

Then, why was the separation of law necessary to protect the farmers? Table 2 shows the relationship of the control of cultivation and medical use of narcotics with the $\mathrm{CCA}^{11}$ and the NCA. ${ }^{22}$ The CCA allows the cultivation of Cannabis with a cultivator license, but not medical use. On the other hand, the NCA allows medical use of narcotics with a license, but not cultivation. Cultivation of Cannabis has numerous purposes such as for food, fiber, and medicine, whereas other narcotic plants are grown mainly as sources of drugs.

Table 2. Relationship Between Cultivation and Medical Use of Cannabis and Other Narcotics

\begin{tabular}{|c|c|c|c|}
\hline & $\begin{array}{l}\text { Applicable } \\
\text { legislation }\end{array}$ & Cultivation & Medical use \\
\hline Cannabis & CCA & $\begin{array}{l}\text { Allowed with } \\
\text { license }\end{array}$ & Prohibited \\
\hline Narcotics $^{a}$ & NCA & Prohibited $^{b}$ & $\begin{array}{l}\text { Allowed with } \\
\text { license }\end{array}$ \\
\hline
\end{tabular}

${ }^{a}$ Excluding Cannabis.

${ }^{b}$ Only a research license holder can cultivate with authorization of Ministry of Health, Labour and Welfare for study purpose.
If CCA had allowed not only cultivation but also medical use, its enforcement would have been difficult in terms of controlling the medical use because it was laborious to distinguish which Cannabis farms for which uses especially in the confused period just after the end of the war. Therefore, in our opinion, the Japanese Government has stifled the medical use of Cannabis to continue allowing its cultivation by hemp farmers and, thereby, has protected the industry. Indeed, the current version of the CCA only regulates the handling of Cannabis leaves and spikes, which contain psychoactive substances, while the seeds and stem, which are the resource of food and fiber, were excluded from the control. When the laws were enacted in 1948, Cannabis seeds were also subject to the CCA, but were excluded from the control by the third revision of March 17, 1953. This amendment was also intended to simplify the control and facilitate the ease of cultivation.

\section{Problem associated with article 4 of the CCA}

As mentioned previously, although the CCA prohibits the medical use of Cannabis and its extracted products in article 4, it does not regulate the mature stalks, seeds, and related products. It only regulates the leaves and spikes of Cannabis. Therefore, Cannabis-based medicines, which are extracted from the leaves and spikes, such as the phytocannabinoid formulation, nabiximols $\left(\right.$ Sativex $\left.{ }^{\circledR}\right),{ }^{6}$ are subject to the CCA and not approved for use in humans. On the other hand, dronabinol (Marinol $\left.^{\circledR}\right)^{7}$ or nabilone (Cesamet $\left.{ }^{\circledR}\right),{ }^{23}$ constituted from synthetic tetrahydrocannabinol and not Cannabis, is not subject to the CCA and therefore may possibly be investigated in clinical trials. Indeed, a clinical trial of dronabinol was planned according to the research report of the Ministry of Health, Labour and Welfare (MHLW)funded project, ${ }^{24}$ but was not initiated. Moreover, rimonabant (Acomplia ${ }^{\circledR}$ ), the synthetic cannabinoid receptor 1 antagonist, was clinically investigated as a weight-loss drug in Japan; however, the trial was terminated due to evidence of an unfavorable neuropsychiatric adverse reaction in other trials in $2009 .{ }^{25,26}$ From a scientific viewpoint, there is no plausible reason to allow the clinical investigation of synthetic cannabinoids, but not phytocannabinoids.

In 1948, cannabinoids and the endocannabinoid system had not yet been discovered, and the therapeutic properties of Cannabis were not well investigated or provided with a scientific basis. However, the scientific discovery process of the cannabinoids has been accelerated, which includes investigation of efficacy and safety 
profiles in clinical trials and this has initiated global approval of phytocannabinoid-based medicines. Therefore, there is no current plausible reason for the regulatory prohibition of investigations of phytocannabinoid-based medicines in Japan. The evidence of the existence of an endocannabinoid system implies that phytocannabinoids are potentially useful substances for medical applications. The argument that the clinical investigation of synthetic cannabinoids, which is permitted under the current regulation, is sufficient for pharmacological assessments in drug development may be proffered. However, synthetic cannabinoid medicines usually consist of a single agent, while phytocannabinoid-based medicines and medicinal Cannabis contain various types of cannabinoids as well as terpenoids that might induce the entourage effects to complementary therapeutic activities. ${ }^{27}$ Therefore, by focusing on potential phytocannabinoid-terpenoid synergistic effects, pharmaceutical development of phytocannabinoids could advance the pharmaceutical frontier of novel drug discovery.

Ultimately, reforming the regulations would be an ethical response to patients who have been appealing for the access to treatment of their diseases with possible phytocannabinoid-based medicines. The regulations need to be positively revised to meet the medical requirements and rights of the patients. It is noteworthy that in 1999, a patient advocacy group commenced appeals for the revision of the CCA in Japan. However, as a prerequisite for the revision, stakeholders need to cooperate with legal professionals to establish a new comprehensive regulatory system to strictly guide the appropriate use of cannabinoid-based medicines, including medical Cannabis. It is important to prevent the risk of any abuses or evasions of law by learning lessons from the precedents of other countries and developing rigid schemes to control cannabinoid-based medicine, especially medical Cannabis. Legislating a compassionate use program might be one of the choices to improve the current situation without revising article 4 of the CCA. Moreover, the authors are not in a position to deregulate the recreational use of Cannabis.

\section{Article 4 of the CCA awaits appropriate revision}

The demonstration of the existence of the endocannabinoid system in the human body implies that cannabinoids are essential substances and they can be positively applied as therapies for various symptoms and diseases. There are over 200 basic research studies on cannabinoids that have been supported by the Grants-in-Aid for Scientific Research from the MEXT, and more than 10 of the investigated topics are intended to innovate the drug development or clinical application of Cannabinoids. ${ }^{1}$ Unfortunately, these basic research findings on phytocannabinoids cannot be translated to clinical studies due to the current regulation in Japan. These regulatory prohibitions have contributed to creating the valley of death, which may be difficult to overcome without revising article 4 of the CCA or creating new regulations such as a compassionate use program. Phytocannabinoids have been neglected as potentially beneficial therapeutic agents in clinical research for almost 70 years in Japan.

Fortunately, Japan recently stepped up efforts to institutionalize changes to foster the Japanese medical research environment. The Independent Administrative Agency of Japan, Agency for Medical Research and Development (AMED), which commenced activities in April 2015, ${ }^{28}$ was established based on new laws called the Acts on Promotion of Healthcare and Medical Strategies and the Establishment of AMED. AMED aims to promote integrated research and development in the field of medicine from basic research to clinical trials by consolidating budgets for research expenses, which were previously allocated to several ministries such as the MEXT and MHLW for basic and clinical research, respectively. ${ }^{28}$ Japan is currently reforming the medical research environment to resolve drug development lapses and promote innovate research areas, including regenerative medicine and oncology. Thus, the nation now has a conducive environment and the opportunity to positively revise the regulation on cannabinoids. The government, academia, industries, and medical and legal professionals need to come together cooperatively and address these issues with all seriousness and a view to resolving them.

\section{Conclusion}

Currently, clinical research on phytocannabinoids is prohibited in Japan based on regulations that were instituted during the postwar period of World War II, which have contributed to the valley of death in cannabinoid translational research. These prohibitive regulations have been an undesired obstacle to the phytopharmacological development of Cannabis for almost 70 years. Scientific discoveries in cannabinoid research have accelerated our understanding of the potential benefits of these agents. Consequently, there have been positive reforms of the regulations governing Cannabis globally, and Japanese regulatory bodies are 
now faced with the window of opportunity to revise article 4 of the CCA.

\section{Acknowledgments}

This work was supported by the Grants-in-Aid for Young Scientists (B), MEXT/JSPS KAKENHI Grant Number 26860353. The first author would like to thank Mr. Koichi Maeda of the Japan Medical Marijuana Association and Dr. Kazunori Fukuda of the Ginza Tokyo Clinic, Japan.

\section{Author Disclosure Statement}

No competing financial interests exist.

\section{References}

1. Kaken Database of Grants-in-Aid for Scientific Research [database on Internet]. Available at: https://kaken.nii.ac.jp/en/ [accessed Apr 9, 2015].

2. Sugiura T, Kondo S, Sukagawa A, et al. 2-Arachidonoylglycerol: a possible endogenous cannabinoid receptor ligand in brain. Biochem Biophys Res Commun. 1995;215:89-97.

3. Mechoulam R, Ben-Shabat $S$, Hanus $L$, et al. Identification of an endogenous 2-monoglyceride, present in canine gut, that binds to cannabinoid receptors. Biochem Pharmacol. 1995;50:83-90.

4. Grotenhermen F, Russo EB. Cannabis and cannabinoids: pharmacology, toxicology, and therapeutic potential. Haworth Press: Binghamton, NY 2002.

5. Reggio HP. The cannabinoid receptors (the receptors). Humana Press: Greensboro, NC, 2009.

6. Sativex prescriber information [Internet]. Available at: www.gwpharm .com/prescriberinformation.aspx [accessed Mar 31, 2015].

7. Orange Book: Approved drug products with therapeutic equivalence evaluations [retrieval system on Internet]. Available at: www.accessdata .fda.gov/scripts/cder/ob/docs/obdetail.cfm?Appl_No=018651\&TABLE $1=O B \_R x$ [accessed Jul 2, 2015]

8. Legal information by State \& Federal Law [retrieval system on Internet]. Available at: www.safeaccessnow.org/state_and_federal_law [accessed Mar 31, 2015]

9. Search orphan drug designations and approvals [retrieval system on Internet]. Available at: www.accessdata.fda.gov/scripts/opdlisting/oopd/ OOPD_Results_2.cfm [accessed Apr 03, 2015]

10. Cannabidiol for the treatment of dravet syndrome EU: Committee for orphan medicinal products [retrieval system on Internet]. Available at: www.ema.europa.eu/ema/index.jsp?curl=pages/medicines/human/ orphans/2014/11/human_orphan_001425.jsp\&mid=WC0b01ac058001d12b [accessed Mar 31, 2015]

11. Cannabis Control Act. July 10, 1948 [Internet]. Available at: http://law .e-gov.go.jp/htmldata/S23/S23HO124.html (in Japanese) [accessed Dec 7, 2015].

12. Japanese Law Translation Database System [database on Internet] Available at: www.japaneselawtranslation.go.jp/law/detail/?id= $2594 \& v m=04 \& r e=02 \& n e w=1$ [accessed Dec 7, 2015 ].

13. Diet proceedings search system [database on the Internet]. Available at http://kokkai.ndl.go.jp/ (in Japanese) [accessed Mar 31, 2015].

14. Japanese Law Translation Database System [database on Internet]. Available at: www.japaneselawtranslation.go.jp/dict/download?re $=02$ [accessed Jun 1, 2015]

15. Takemae E. GHQ Shireisoushusei (Total collection of GHQ instructions) MT shuppan: Tokyo, Japan, 1993-1994 (in Japanese).

16. Control of narcotic products and records in Japan, memorandum on SCAPIN 130. Oct 12, 1945 [database on Internet]. Available at: http:// iss.ndl.go.jp/books/R100000002-I000006847238-00 [accessed Mar 31, 2015].

17. Establishment of an effectives system for narcotic control in Japan memorandum on SCAPIN 644. Jan 22, 1946 [database on Internet]. Available at: http://iss.ndl.go.jp/books/R100000002-I000006847787-00 [accessed Mar 31, 2015].
18. Olson D. Hemp culture in Japan. J Int Hemp Assoc. 1997;4:40-50.

19. International Convention, Adopted by the Second Opium Conference (League of Nations), and Protocol relating thereto. Signed at Geneva, Feb 19, 1925 [database on Internet]. Available at: www.worldlii.org/int/other/ LNTSer/1928/231.html [accessed Aug 5, 2015].

20. Yamamoto I. Taima: Hikari to yami. Kyoto Hirokawa Shoten: Tokyo, Japan 2012 (in Japanese)

21. National diet proceedings search system [database on Internet]. Available at: http://kokkai.ndl.go.jp/(in Japanese) [accessed Mar 31, 2015].

22. Narcotics and Psychotropics Control Law. March 17, 1953 [Internet]. Available at: http://law.e-gov.go.jp/htmldata/S28/S28HO014.html (in Japanese) [accessed June 26, 2015].

23. Orange Book: Approved Drug Products with Therapeutic Equivalence Evaluations [retrieval system on Internet]. Available at: www.access data.fda.gov/scripts/cder/ob/docs/obdetail.cfm?Appl_No=018677 \&TABLE 1=OB_Rx [accessed Jul 2, 2015].

24. MHLW grants system [database on the Internet]. Available at: https:// mhlw-grants.niph.go.jp/niph/search/NIDD00.do?resrchNum $=201118012 \mathrm{~A}$ [accessed Mar 31, 2015].

25. ClinicalTrials.gov [database on Internet]. Available at: www.clinicaltrials.gov/ct2/show/NCT00478972 [accessed Jul 3, 2015]

26. Kwatra SG. Termination of the CRESCENDO trial. Lancet. 2010;376:1984

27. Russo EB. Taming THC: potential cannabis synergy and phytocannabinoidterpenoid entourage effects. Br J Pharmacol. 2011;163:1344-1364.

28. About AMED [Internet]. Available at: http://www.amed.go.jp/en/ [accessed Jul 2, 2015].

Cite this article as: Miyaji T, Nagasawa M, Yamaguchi T, Tsutani K (2016) Tackling the pharmaceutical frontier: regulation of cannabinoid-based medicines in postwar Japan, Cannabis and Cannabinoid Research 1.1, 31-37, DOI: 10.1089/can.2015.0011.

$\begin{aligned} & \text { Abbreviations Used } \\ & \text { AMED }=\text { Japan Agency for Medical Research and Development } \\ & \mathrm{CCA}=\text { Cannabis Control Act } \\ & \mathrm{GHQ}=\text { general headquarters } \\ & \mathrm{HoC}=\text { House of Councilors } \\ & \mathrm{HoR}=\text { House of Representatives } \\ & \mathrm{MEXT}=\text { Ministry of Education, Culture, Sports, Science and Technology } \\ & \mathrm{MHLW}=\text { Ministry of Health, Labour and Welfare } \\ & \mathrm{NCA}=\text { Narcotics Control Act } \\ & \text { SCAP }=\text { Supreme Commander for the Allied Powers }\end{aligned}$

Publish in Cannabis and Cannabinoid Research
Cannabis and Cannabinoid Research
- Immediate, unrestricted online access

- Rigorous peer review

- Compliance with open access mandates

- Authors retain copyright

- Highly indexed

- Targeted email marketing liebertpub.com/can 